\title{
Synthesis and Characterization of Modified Polystyrene with Oleic Acid and an Allyl Ester Derivative
}

\author{
Bruno Henrique Lattmann ${ }^{a}$, Carlos Eduardo Lunelli ${ }^{a}$, Duanne M. Scremin ${ }^{a}$, Bianca Padilha ${ }^{a}$, \\ Eduardo Marques Trindade ${ }^{a}$, Sônia Faria Zawadzki ${ }^{a *}$
}

${ }^{a}$ Departamento de Química, Universidade Federal do Paraná, Curitiba, PR, Brasil

Received: December 17, 2018; Revised: June 29, 2019; Accepted: July 07, 2019

\begin{abstract}
Polystyrene (PS) is one of the most widely used polymers in the world, having a wide applicability. PS can be used in pure or modified forms, and the commercial materials most used for modifications are non-renewable and have high costs. For this reason, studies have been carried in order to evaluate renewable components application such as vegetable oils, for this purpose. In this context, different materials have been prepared from styrene (STY) and the common fatty oleic acid (FA) modified with allyl alcohol through esterification in acid catalysis. The allyl oleate (AOL) was obtained with yield of $89 \%(\mathrm{w} / \mathrm{w})$ and it was submitted to a reaction with styrene at variable concentrations. The copolymers (PS-AOL) were obtained and characterized by conventional techniques. The results indicated that the copolymerization occurred. Therefore, the proposed methodology allows the compatibilization between a renewable matrix and PS for the new materials obtaining.
\end{abstract}

Keywords: Polystyrene, allyl oleate, esterification, copolymer.

\section{Introduction}

A large number of polymers applications results from their early properties and the way they are processed. In order to increase these applications and also to improve some properties, it is common in polymer industry to undergo by synthesis modifications ${ }^{1}$. Polystyrene (PS) is inserted in this context as a versatile material that can usually be traded or commercialized in standard, expanded (EPS) and high impact (HIPS) forms ${ }^{2}$. These types of PS are employed as pure or modified, being the HIPS usually made from non-renewable materials with high cost. Many researches propose the modification of PS in order to promote changes using renewable raw materials which strategies add an ecological proposal for the material. Some researches show the addition of vegetable fibers to PS for reinforcement, the addition of lignin in the PS composition of hydrophobic surfaces, or the use of polysaccharides for the composition of PS-based food packaging, and the use of corn starch for PS copolymerization ${ }^{3-7}$.

The use of vegetable oils (or their fatty acids, FA) in compositions with STY is a real possibility for new composites. According to Sharma and $\mathrm{Kundu}^{8}$, the possibility of polymerization of FA is feasible since in their structure, many double bonds are found and available. Therefore, there is a favored radical polymerization reaction through the hydrogen in the allyl position, due to the higher reactivity of this hydrogen (Figure 1), creating a distinct monomer (FA), in order to achieve a copolymerization with the PS. This copolymerization would be similar to that which occurs in HIPS formation between STY and polybutadiene ${ }^{9,10}$.

*e-mail: zawadzki@ufpr.b

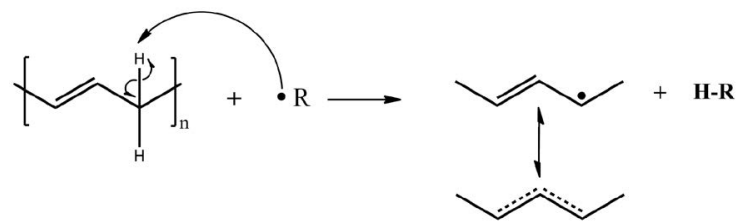

Figure 1. Representation of the abstraction of the allylic hydrogen by free radical and the resonance form.

Although it is quite mentioned in the literature, the polymerization between vegetable oils in natura and vinyl monomers is not easy to occur ${ }^{11}$. A proposed alternative consists on increasing the number of active sites on the vegetable oil thought an esterification process of fatty acids using unsaturated alcohols.

Therefore, the present work aims to prepare and analyze some compositions of polystyrene modified with fatty acids from vegetable oils (oleic acid) and their derivative allyl esters. The synthesis of these new materials can bring economic and environmental advantage, due to the use of low cost reagents and their renewable matrix.

\section{Materials and Experiment Procedures}

\subsection{Materials}

Amberlyst-15: (commercial sulfonic acid catalyst) -4.7 mmol SO $\mathrm{H} \mathrm{g} \mathrm{g}^{-1}$; specific area: $50 \mathrm{~m}^{2} \mathrm{~g}^{-1}$; pore volume: 0.40 $\mathrm{cm}^{3} \mathrm{~g}^{-1}$; average diameter of pores: $300 \AA$; particle size: 0.600 to $0.850 \mathrm{~mm}$ (Rohm \& Haas); anhydrous sodium sulphate: $99 \%$ (Neon); chloroform 99.8\% (LabSynth); methanol: 98\% (Vetec) and oleic acid: 90\% (Sigma-Aldrich). 
All these materials were used as received. Allyl alcohol, 98\% (Carlos Erba), was distilled. Amberlyst-15 was treated with a $10 \% \mathrm{HCl}$ aqueous solution (v/v) for 30 minutes, filtered, washed with distilled water, and dried at $70^{\circ} \mathrm{C}$. Benzoyl peroxide, 99\%, unknown source, was recrystallized using chloroform and cold methanol. Styrene: 99\% (SigmaAldrich) was treated to remove inhibitor traces by washing with $\mathrm{NaOH}$ aqueous solution 5\% (w/v) and under vacuum distilled.

\subsection{Methods}

\subsubsection{Esterification reaction between oleic acid and allyl alcohol}

The esterification process was conducted in a $100 \mathrm{~mL}$ flask in a heating system, magnetically stirred and under reflux. The acid catalyst Amberlyst-15 was added to the flask in the $5 \%$ ratio $\left(\mathrm{w}_{\text {cat }} / \mathrm{w}_{\text {oleic acid }}\right)$. In sequence, it was added oleic acid and allyl alcohol mixture in 1:10 ratio. The reaction was carried out at $80^{\circ} \mathrm{C}$ for $7 \mathrm{~h}$. The product was filtered, and vacuum distilled at $110^{\circ} \mathrm{C}$ for alcohol excess removal. The product was again subject to a new esterification reaction, for $5 \mathrm{~h}$ at $90^{\circ} \mathrm{C}$. The material was filtered and, once more, vacuum distilled. To the distillate product was added water for the extraction of residual alcohol. A new extraction process was done using chloroform and, after partition, the product was vacuum evaporated for solvent removal. Following this procedure, the allyl oleate was obtained and nominated AOL.

\subsubsection{Polymerization of styrene with allyl ester or oleic acid}

The polymerization reaction was conducted in a twomouth flask connected to a system with calcium chloride for moisture reduction. The reaction was carried out through a heated system and magnetic stirring. The AOL and the benzoyl peroxide (PBO) (Table 1) were added and stirred at $120^{\circ} \mathrm{C}$ for $1 \mathrm{~h}$ in nitrogen atmosphere. Then, the system was cooled up to $90^{\circ} \mathrm{C}$ add styrene was added drop by drop.
The reaction was kept under constant conditions until the viscosity increase that was an indication of the polymer production. The final product was transferred to a glass mold and submitted to cure at $85^{\circ} \mathrm{C}$ for a variable time depending on the composition. With this procedure the compositions were obtained and named PS-AOL. In parallel, it was conducted, in same conditions, reactions with oleic acid. The compositions were called PS-OAC.

\subsection{Characterization}

The products synthetized in this work were characterized by the following techniques: allyl oleate ester: FT-IR, ${ }^{1} \mathrm{H}$ NMR and DSC. PS-AOL or PS-OAC compositions: FTIR, GPC, DSC and MEV. All analyses were performed at Federal University of Paraná laboratories.

\subsubsection{Titration of the esterification product}

The titration procedure was performed with a standardized aqueous solution of $0.01 \mathrm{molL}^{-1} \mathrm{NaOH}\left(9.043 \mathrm{mmolL}^{-1}\right)$ in triplicate. The sample was prepared by weighing two drops of the product $(20-30 \mathrm{mg}$ ) solubilized in $5 \mathrm{ml}$ of ethanol with the addition of two drops of an ethanolic solution of phenolphthalein. The titration proceeded to the turning point. The consumed aqueous solution $\mathrm{NaOH}$ volume was noted and it was possible to calculate the number of moles and the weight of oleic acid remaining to determine the ester yield.

\subsubsection{Fourier transform infrared (FT-IR) spectroscopy}

The products (allyl ester and PS compositions) were analyzed by FT-IR. The analyses were performed on the Bomem MB Series in the infrared region between 4000 and $400 \mathrm{~cm}^{-1}, 32$ scans per minute and a resolution of $4 \mathrm{~cm}^{-1}$.

\subsubsection{Nuclear magnetic resonance spectroscopy $(N M R)^{1} H$.}

The samples were prepared in deuterated chloroform $\left(\mathrm{CDCl}_{3}\right)$ with $0.1 \%$ TMS, used as reference. Using a nuclear magnetic resonance spectrometer Bruker $200 \mathrm{MHz}$, the materials were analyzed by ${ }^{1} \mathrm{H}$ NMR.

Table 1. Reaction conditions for obtaining the material compositions: sty and allyl oleate (PS-AOL) or sty and oleic acid (PS-OAC).

\begin{tabular}{|c|c|c|c|c|}
\hline Co-monomer & Code & $\%$ co-monomer & $\begin{array}{l}\text { Prepolymer reaction } \\
\text { time }\end{array}$ & Curing time (h) \\
\hline \multirow{4}{*}{ 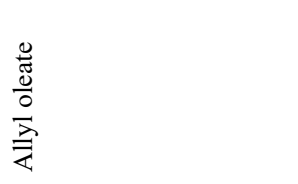 } & PS-AOL 2 & 2 & $2 \mathrm{~h} 40 \mathrm{~min}$ & 24 \\
\hline & PS-AOL 5 & 5 & $3 \mathrm{~h} 15 \mathrm{~min}$ & 36 \\
\hline & PS-AOL 10 & 10 & $3 \mathrm{~h} 50 \mathrm{~min}$ & 42 \\
\hline & PS-AOL 15 & 15 & 4h 40 min & 54 \\
\hline : & PS-OAC 5 & 5 & $3 \mathrm{~h} 00 \mathrm{~min}$ & 55 \\
\hline$\frac{\frac{0}{0}}{0}$ & PS-OAC 10 & 10 & $5 \mathrm{~h} 00 \mathrm{~min}$ & 96 \\
\hline
\end{tabular}

\footnotetext{
* PBO content: $1 \%(\mathrm{w} / \mathrm{wsty})$
} 


\subsubsection{Differential scanning calorimetry (DSC)}

The DSC was performed on the NETZCH DSC 200 F3 Maia calorimeter at a constant heating and cooling rates of $10^{\circ} \mathrm{C} \cdot \mathrm{min}^{-1}$, from room temperature to $150^{\circ} \mathrm{C}$ and cooled to $-130^{\circ} \mathrm{C}$, under constant nitrogen flow $(40$ $\mathrm{mL} \cdot \mathrm{min}^{-1}$ ), with 5 minutes isotherm. The specific heating/ cooling sequential conditions for each sample were defined at the time of conducting the experiments. The products were weighed (approximately $10 \mathrm{mg}$ ) and analyzed into aluminum crucibles. The equipment was calibrated with standard indium (melting point $167^{\circ} \mathrm{C}$ ).

\subsubsection{Gel permeation chromatography (GPC)}

It was used a Shimadzu LC10AD system equipment

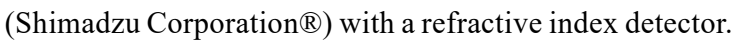
Two Tosoh TSH-gel columns (Tosoh Corporation $®$ ) were used and $10 \mathrm{mg}$ of the copolymers were dissolved in tetrahydrofuran (THF). The analyses were performed at $45^{\circ} \mathrm{C}$ and THF was used as mobile phase in a flow rate of $1.0 \mathrm{mLmin}^{-1}$. The molecular weight was determined once the equipment was calibrated with monodisperse standard polystyrene, dimethylbenzene and anthracene.

\subsubsection{Scanning electron microscopy (SEM)}

It was used a TESCAN VEGA3 LMU scanning electron microscope with $3 \mathrm{~nm}$ resolution. The samples were analyzed with magnifications of $5 \mathrm{kX}$ and $10 \mathrm{kX}$ under $30 \mathrm{~Pa}$ and $25 \mathrm{kV}$ electron beam. The surfaces of the samples were coated with gold.

\section{Results and Discussion}

\subsection{Esterification}

The allyl oleate ester (Figure 2) was produced through the esterification reaction of oleic acid in excess of allyl alcohol using acid catalyst Amberlyst-15.

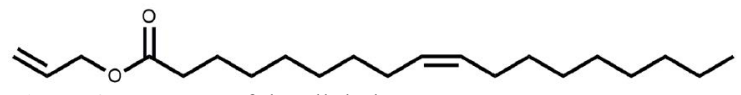

Figure 2. Structure of the allyl oleate.

For this process, a methodology was developed employing a two steps reaction, in order to optimize the process. The total yield was initially calculated by a titration of the oleic acid using sodium hydroxide aqueous solution $(0.01 \mathrm{M})$, in triplicate. It was observed that, at the end of the first step, the reaction had an average yield of $70.78 \%$ and at the end of the second step, got up to $87.07 \%$.

Another method to determine the yield of the esterification was the direct quantification of esters by ${ }^{1} \mathrm{H}$ NMR as reported by Rosset ${ }^{12}$. This method compares the signal from the chemical shift of the alpha-carboxylic hydrogen (triplet) of the oleic acid (at $2.34 \mathrm{ppm}$ ) with the ones that belong to the ester (at $2.28 \mathrm{ppm}$ ). If there is a mixture, the signals will overlap, and the multiplet will be shifted, becoming more prominent on the component in excess. The ester percentage at the end of the reaction was determined by Equation 1 based on the values of the signals found on the spectrum, at which $\mathrm{A}_{1}$ is the rightmost signal of the multiplet and $\mathrm{A}_{3}$ is the total signal length.

$$
\text { \%ester }=\frac{4 A_{1}}{A_{3}}
$$

The ${ }^{1} \mathrm{H}$ NMR spectrum of the allyl ester is shown in Figure 3 and it was used for the ester percentage calculation, based on the theoretical behavior indicated in the upper right corner. It was observed that the signals related to the ester are more pronounced than the acid signals (spectrum not shown), suggesting a higher proportion of ester. The calculation of ester production (\%) is shown below, where $\mathrm{A}_{1}$ ( 2.36 to 2.39 $\mathrm{ppm}$ ) has a signal length equal to 9.47 and $\mathrm{A}_{3}$ equal to 42.56 . The yield was $89 \%$, a similar result determined by titration.

$$
\frac{4 .(9.47)}{33.09+9.47}=\frac{37.88}{42.56}=0.8900=89.00 \%
$$

\subsection{Copolymer synthesis}

The copolymers were synthesized from styrene (STY) and allyl oleate (AOL) or oleic acid (OAC). Since the allyl oleate has a terminal double bond besides an unsaturation in the middle of the carbon chain, it has an additional route for the radical polymerization with STY. The reaction of copolymerization with AOL may occur in two ways (Figure 4): the first by the abstraction of the allylic hydrogen of the double bond of the same part of the structure and the second by the opening of this terminal unsaturation, considering that this terminal double bond is more available.

During the experiments it was observed that the higher the percentage of allyl oleate in the formulation, the longer the time required for the reaction medium to reach a suitable viscosity. The curing time also increased directly. The copolymers were obtained in plates and showed different aspects. PS-AOL 2 and PS-AOL 5 were translucent, PS-AOL 10 was slightly cloudy, while PS-AOL15 became completely whitish. The copolymers based on PS and OAC showed whitish aspect for all compositions.

\subsection{Gel permeation chromatography (GPC)}

The copolymers were analyzed by gel permeation chromatography (GPC) and the data are shown in Table 2.

Higher molecular weight values were obtained for the copolymers PS-AOL 2 and PS-AOL 5. This behavior suggests that there is an interference due to the presence of the oleate in the copolymerization, perhaps a possible saturation (or excess) of the ester compound. 


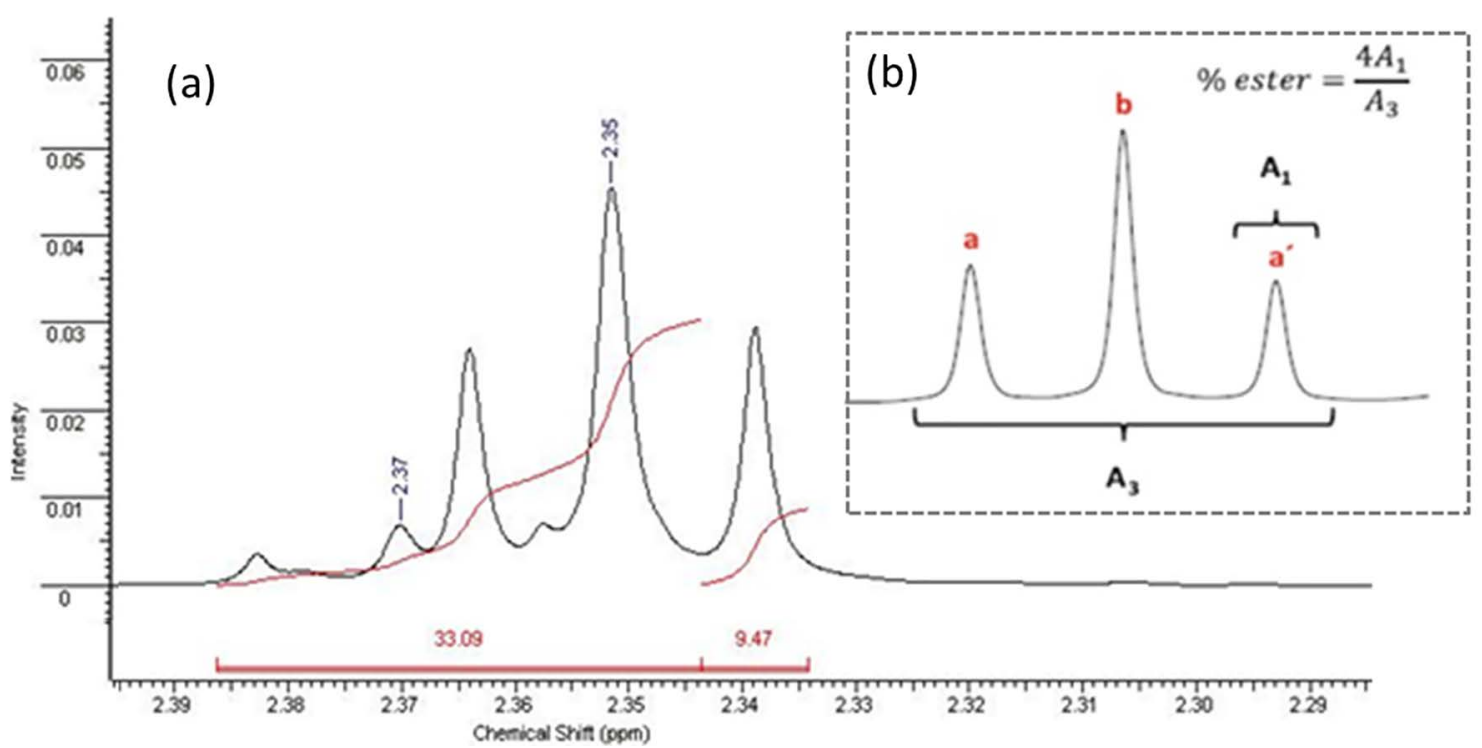

Figure 3. ${ }^{1} \mathrm{H}-\mathrm{NMR}$ spectra (200 mHz, $\mathrm{C}_{3} \mathrm{D}_{6} \mathrm{O}$, TMS). (a) Final product (allyl oleate) spectrum. (b) Theoretical spectrum and equation for ester direct quantification ${ }^{[12]}$. Magnification between 2.28 and $2.40 \mathrm{ppm}$.
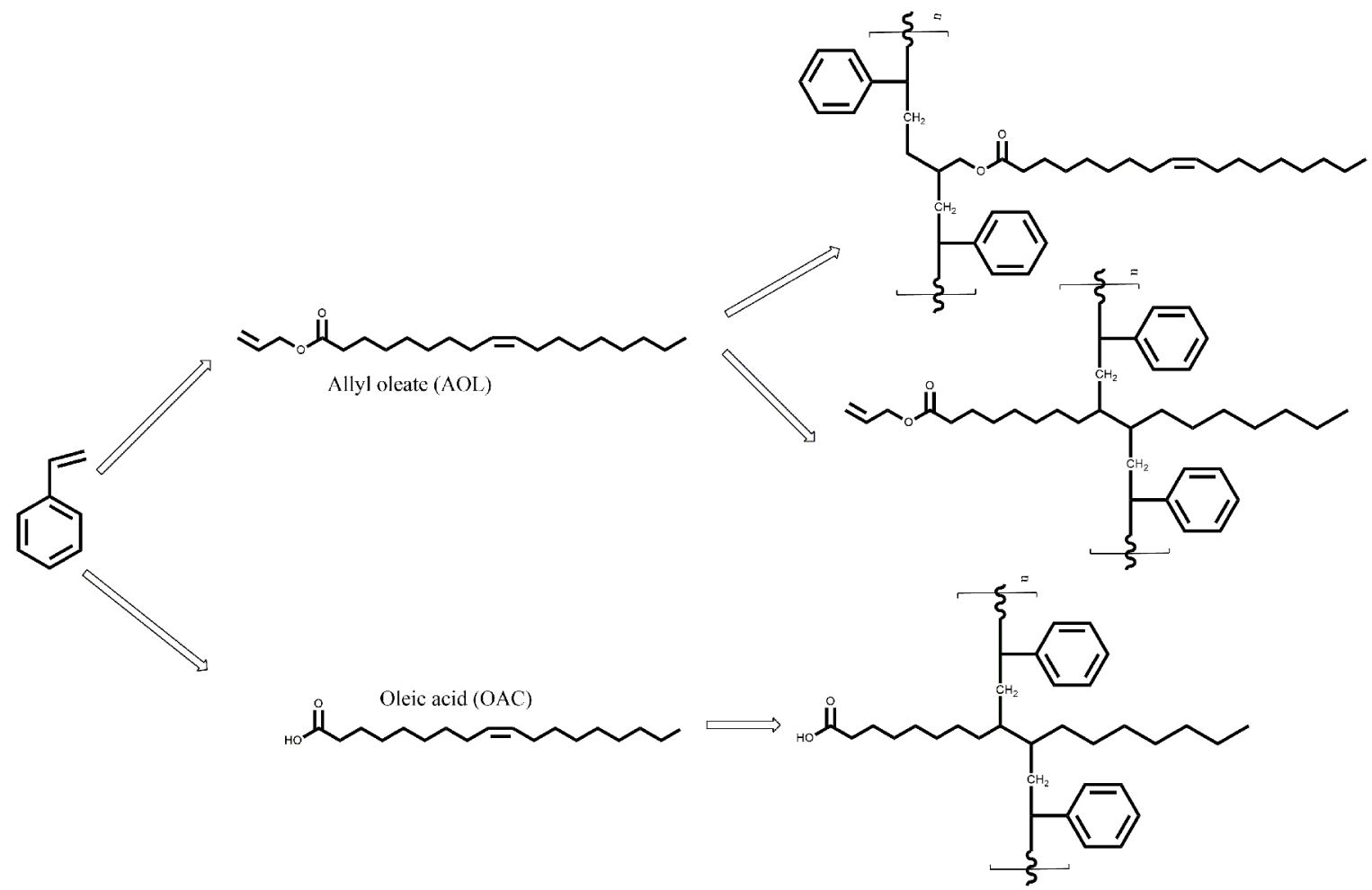

Figure 4. Copolymerization between styrene (STY) and allyl oleate (AOL): products proposal.

Table 2. Molecular weitght of the copolymers produced with styrene and allyl oleate by GPC.

\begin{tabular}{lccc}
\hline Product & $\mathrm{Mn}$ & $\mathrm{Mw}$ & Polydispersity \\
\hline PS & 58,432 & 88,109 & 1.507 \\
PS-AOL 2 & 51,232 & 56,060 & 1.094 \\
PS-AOL 5 & 55,676 & 64,386 & 1.156 \\
PS-AOL 10 & 44,395 & 50,648 & 1.141 \\
PS-AOL 15 & 43,377 & 49,853 & 1.149 \\
\hline
\end{tabular}

Thus, for compositions with $10 \%$ and $15 \%$ oleate, copolymers with lower molecular weight and unreacted ester excess were obtained. However, it was not observed, on the GPC analysis, the reference peak of the ester. As the molecule of the ester has a lower molecular weight, its retention time is around 60 minutes ${ }^{13}$. Since the experimental procedure lasted for 17 minutes, this peak could not be observed. 


\subsection{Fourier transform infrared (FT-IR) spectroscopy}

The FT-IR analysis revealed characteristics bands of polystyrene harmonic absorbance between 2000 and 1750 $\mathrm{cm}^{-1}$ and at $800 \mathrm{~cm}^{-1}, 740 \mathrm{~cm}^{-1}$ and $610 \mathrm{~cm}^{-1}$, indicating that the aromatic ring is monosubstituted. It was also observed the band on $1745 \mathrm{~cm}^{-1}$ related to the $\mathrm{C}=\mathrm{O}$ group from the allyl oleate. This band, when compared proportionally to the other bands on the same spectrum, become more intense as the allyl oleate content is increased. The FT-IR analysis of the copolymers based on STY and oleic acid reaction revealed the same bands on the spectra, except for the $\mathrm{C}=\mathrm{O}$ bond which absorption arises at $1690 \mathrm{~cm}^{-1}$ (Table 3) ${ }^{12-14}$.

The FT-IR results suggest that the two species are present in the mixture, but it has not been possible to distinguish if both are chemically bonded to form the copolymer or if they are just physically mixtured.

Table 3. FT-IR data for styrene copolymers with allyl oleate or oleic acid.

\begin{tabular}{lc}
\hline Wavenumber $\left(\mathrm{cm}^{-1}\right)$ & Correspondent absorption \\
\hline 2000 and 1750 & $(v)$ Harmonics of aromatic ring \\
1745 & $(v) \mathrm{C}=\mathrm{O}$ of ester \\
1690 & $(v) \mathrm{C}=\mathrm{O}$ of carboxylic acid \\
800,740 and 610 & $(\delta)$ Monosubstituted aromatic ring $\mathrm{C}=\mathrm{C}$ \\
\hline
\end{tabular}

\subsection{Differential scanning calorimetry (DSC)}

DSC analysis can be used to evaluate if a copolymer, or other kind of composition, has a behavior as a miscible or immiscible mixture ${ }^{15,16}$. The thermal events for the copolymers of PS and allyl oleate are shown in Figure 5. It is possible to observe that the glass transition temperature $(\mathrm{Tg})$ decreased as the allyl oleate amount is increased, indicating that the oleate permeates through the PS chains, decreasing the intermolecular interactions.

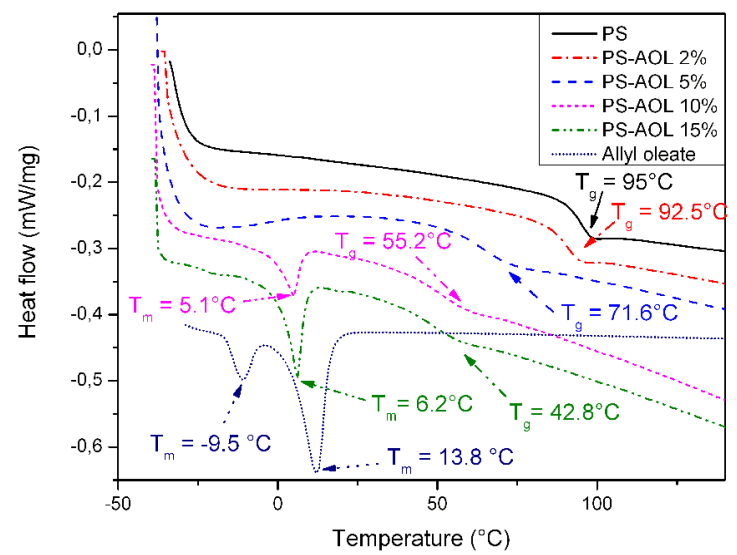

Figure 5. Thermal events determined by differential scanning calorimetry (DCS) for the copolymers of styrene and allyl oleate (second heating curves).
The second heating curve for PS-AOL 2 and PS-AOL 5 showed only one $\mathrm{Tg}$ value, suggesting that these compositions are microscopically homogeneous. For compositions with $10 \%$ and $15 \%(\mathrm{w} / \mathrm{w})$ oleate, DSC curves showed melting events related to the ester. The occurrence of this event indicates that, at these concentrations, allyl oleate did not react entirely with STY. Therefore, for the higher concentrations of oleate, part of it does not react but it remains just arranged between the STY polymer chains, resulting in a decrease in the $\mathrm{Tg}$ value.

It was also performed DSC analyzes for PS-OAC 5 and PS-OAC 10. The second heating curves are shown in Figure 6 and the results of DSC for all copolymers are shown in Figure 7.

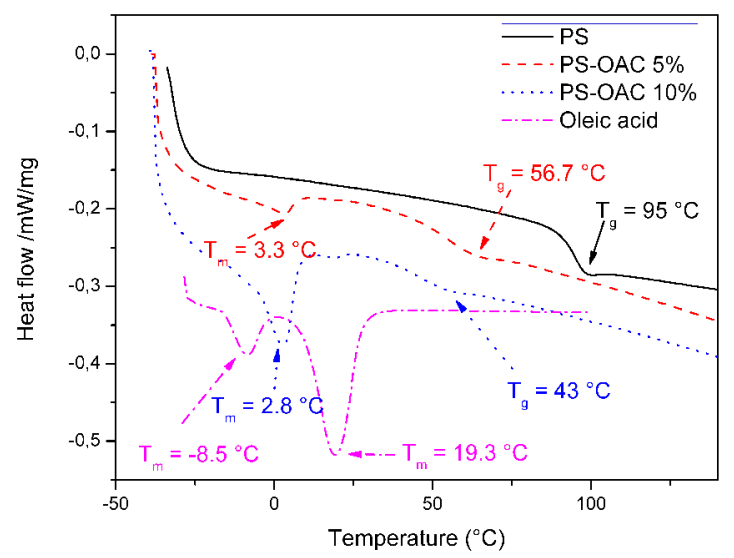

Figure 6. Thermal events determined by differential scanning calorimetry (DCS) for the copolymers of styrene and oleic acid (second heating curves).

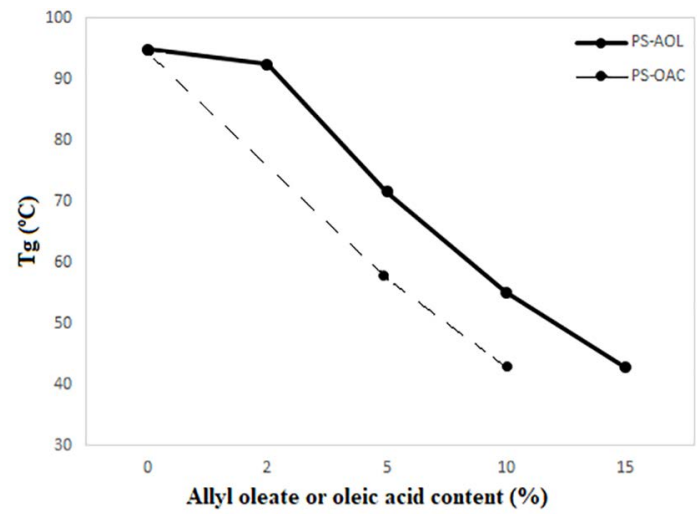

Figure 7. Glass transition temperatures $(\mathrm{Tg})$ variation with the alyl oleate or oleic acid content.

For the compositions based on oleic acid, a decrease in the $\mathrm{Tg}$ value was also observed. This difference was higher than that observed for the oleate compositions, in the same proportions. Nevertheless, the melting event for oleic acid was also observed, even at low concentrations, suggesting that oleic acid interacts favorably with the amorphous part of PS, but probably did not react. 
A reasonable justification that the reaction between oleic acid and styrene did not occur is the need of a higher temperature condition, around $180^{\circ} \mathrm{C}$, in order to the internal double bond became susceptible to radicalar action ${ }^{17}$. However, if the reaction is conducted to this temperature at atmospheric pressure, the styrene would vaporize, since its boiling point is $145^{\circ} \mathrm{C}$. Therefore, the internal double bond of the oleic acid, in the used conditions, is not available for the reaction with styrene.

\subsection{Nuclear magnetic resonance spectroscopy $(N M R)^{1} H$.}

The ${ }^{1} \mathrm{H}$ NMR spectroscopy was a fundamental tool to prove the efficiency of the reaction between styrene and allyl oleate ester. For this evaluation, it was used the ${ }^{1} \mathrm{H}-\mathrm{NMR}$ data related to the allyl portion of the oleate (terminal bond) as reference. The signals of the terminal double bond of the allyl oleate are specific and easy to be identified. The ${ }^{1} \mathrm{H}-\mathrm{NMR}$ evaluation is shown in Figure 8 and their chemical shifts are listed on Table 4.

Table 4. ${ }^{1} \mathrm{H}$ NMR chemical shift of allyl oleate

\begin{tabular}{lc}
\hline$\delta(\mathrm{ppm})$ & Correspondent bond \\
\hline (A) $4.58-4.62$ & Hydrogen in allyl position \\
(B) $5.34-5.38$ & Vicinal hydrogen of the terminal double bond \\
(C) $5.40-5.43$ & \\
(D) $5.89-6.00$ & Internal hydrogen of the terminal double bond \\
\hline
\end{tabular}

The hydrogens directly attached to the inner double bond of the oleate are situated in the same region of the spectrum, approximately 5.4 ppm, of the hydrogens (C) and (D), from the terminal unsaturation ${ }^{14}$. Therefore, the appearance of this signal could indicate that one or both of the bonds do not participate of the copolymerization.
The ${ }^{1} \mathrm{H}-\mathrm{NMR}$ spectra of the copolymers are shown in Figure 9. For the PS-AOL 2 (A) composition, only the signal at $5.38 \mathrm{ppm}$, characteristic of hydrogen bonded to $\mathrm{sp}^{2}$ carbon, is observed, but it is not possible distinguish it from the internal or the terminal double bonds, as previously mentioned. On the other hand, the other signals related to the terminal double bond (at 4.6, 5.42 and $5.9 \mathrm{ppm}$ ) are not observed, suggesting that the reaction occurred by the opening of the double terminal. The allylic hydrogen signal from the terminal unsaturation at approximately $4.6 \mathrm{ppm}$ is also not observed, indicating other reaction possibility. In view of these observations, it can be suggested that the styrene monomer is bound by the terminal portion of the oleate either by the allylic hydrogen abstraction, as by the opening of the unsaturation. In PSAOL 5 (B), it is possible to observe a set of multiplets at 5.1 and $5.4 \mathrm{ppm}$ region related to the double bond at $5.34 \mathrm{ppm}$, that is slightly shifted. These signs are also related to ester hydrogen not conjugated with an unsaturation. Therefore, for PS-AOL 5 composition, it is also concluded that the reaction also occurred by the double terminal, as observed for PS-AOL 2.

The ${ }^{1} \mathrm{H}$ NMR evaluation of PS-AOL 10 (C) and PSAOL 15 (D) showed that it was possible to observe all signals related to the terminal unsaturation of the allyl oleate on the copolymer. This fact indicates the existence of free allyl oleate after the reaction, which means oleate remaining unreacted.

The ${ }^{1} \mathrm{H}$ NMR results indicate that only a part of the allyl oleate was successfully reacted by the terminal unsaturation (up to $5 \%$ of allyl oleate content). Above this value, the oleate reacts but not completely. The unreacted oleate remains trapped in the mixture by favorable intermolecular interactions and form a physical mixing. On Figure 10, it is shown an illustrative scheme of the copolymers obtained.

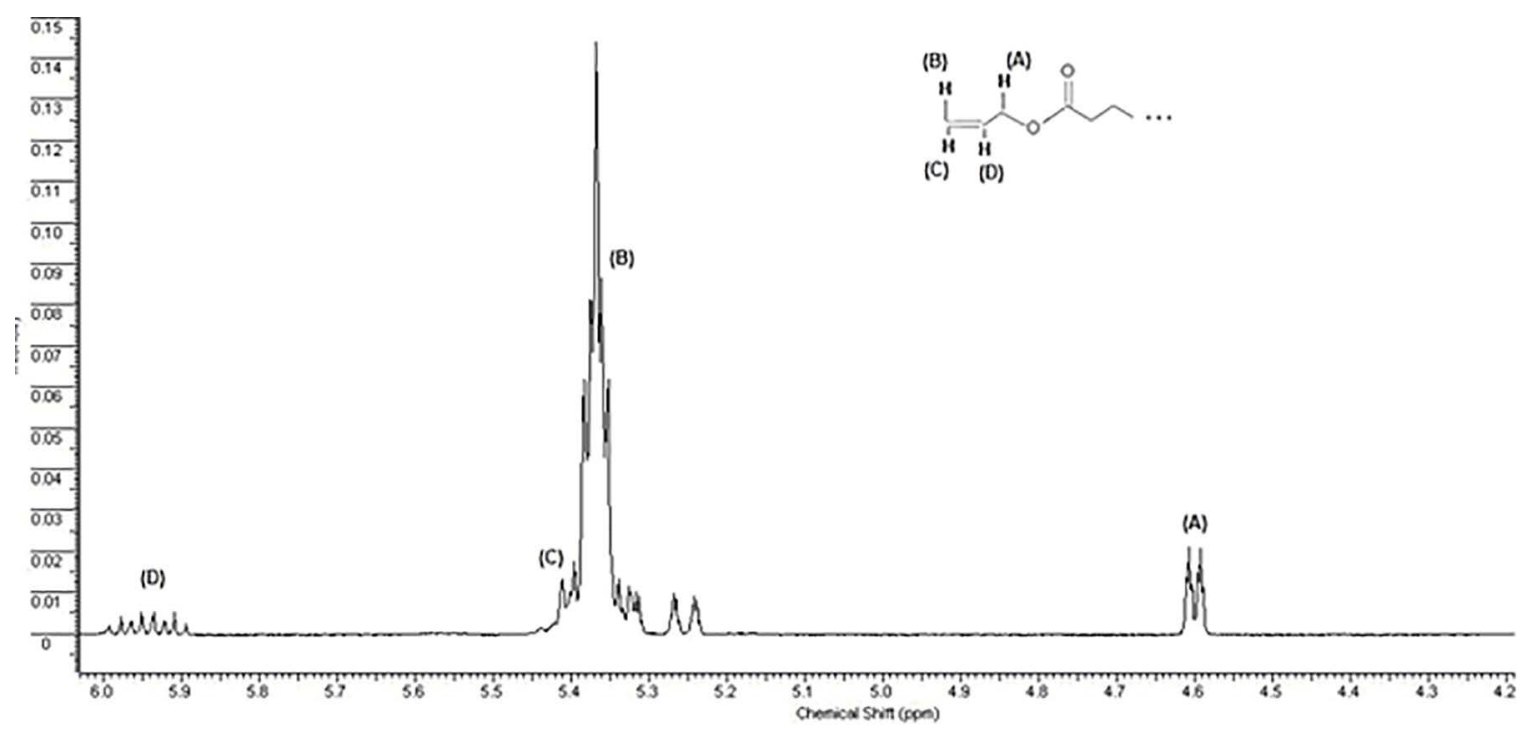

Figure 8. ${ }^{1} \mathrm{H}-\mathrm{NMR}$ spectrum $\left(200 \mathrm{mHz}, \mathrm{C}_{3} \mathrm{D}_{6} \mathrm{O}, \mathrm{TMS}\right)$ of allyl oleate. Magnification in the region of 4.1 to $6.0 \mathrm{ppm}$. 


\subsection{Scanning electron microscopy (SEM)}

The copolymerization products between styrene and allyl oleate or oleic acid were analyzed by SEM. The fractured sides of the plates were inspected with magnification of $5 \mathrm{kX}$ or $10 \mathrm{kX}$. This technique was performed to observe signs of microscopic heterogeneity in the compositions. Figures 11 to 16 show the SEM images.

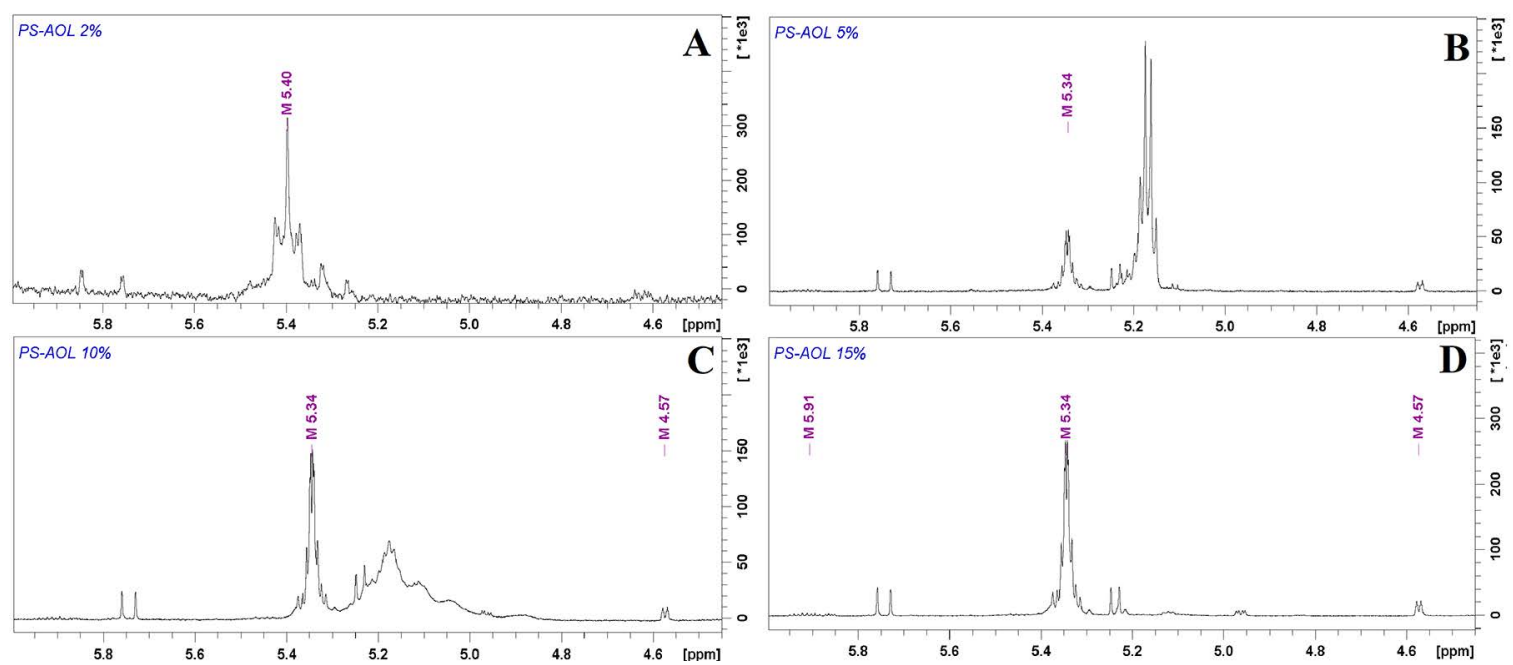

Figure 9. ${ }^{1} \mathrm{H}-\mathrm{NMR}$ spectra $\left(200 \mathrm{mHz}, \mathrm{C}_{3} \mathrm{D} \mathrm{O}\right.$, TMS) of copolymers products. (A) PS-AOL2 \%, (B) PS-AOL $5 \%$, (C) PS-AOL $10 \%$ and (D) PS-AOL15\%. Magnification in the region of 4.4 to $6.0 \mathrm{ppm}$.
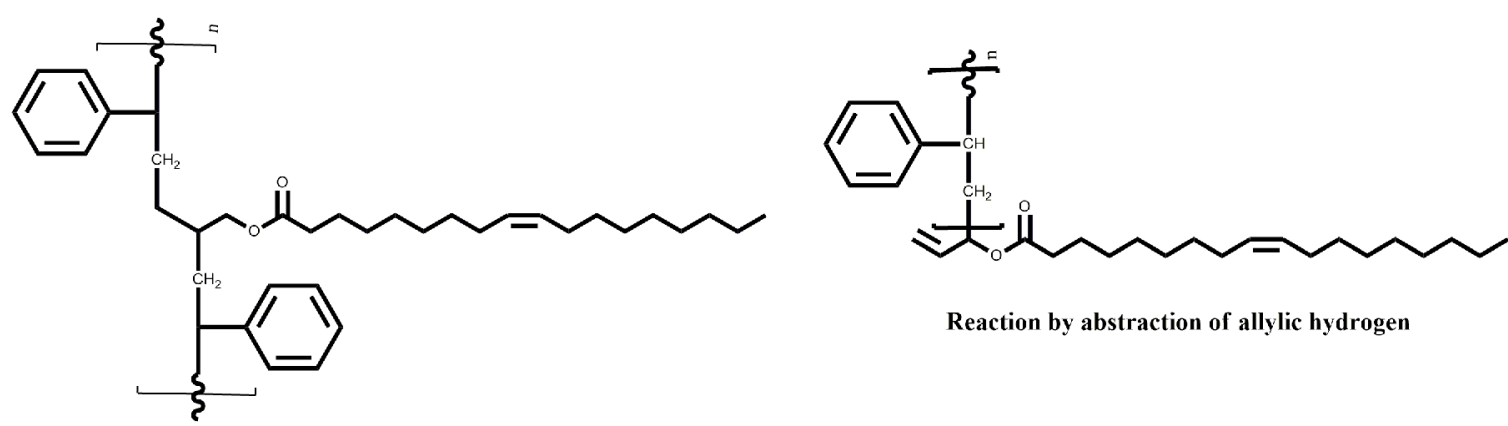

Reaction by the terminal unsaturation

Figure 10. Proposed structure for the copolymer.
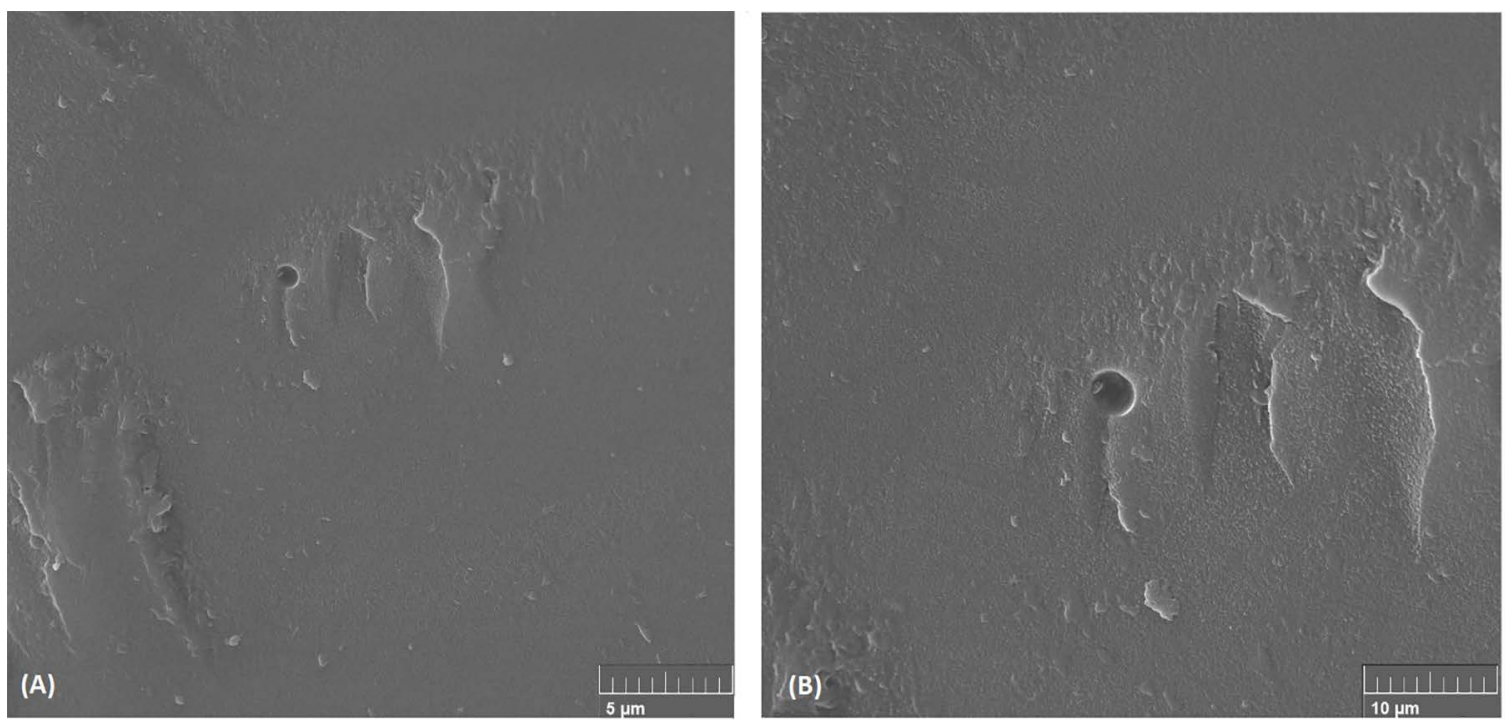

Figure 11. Micrographs of the copolymers PS-AOL $25 \mathrm{kX}$ (A) and $10 \mathrm{kX}(\mathrm{B})$. 

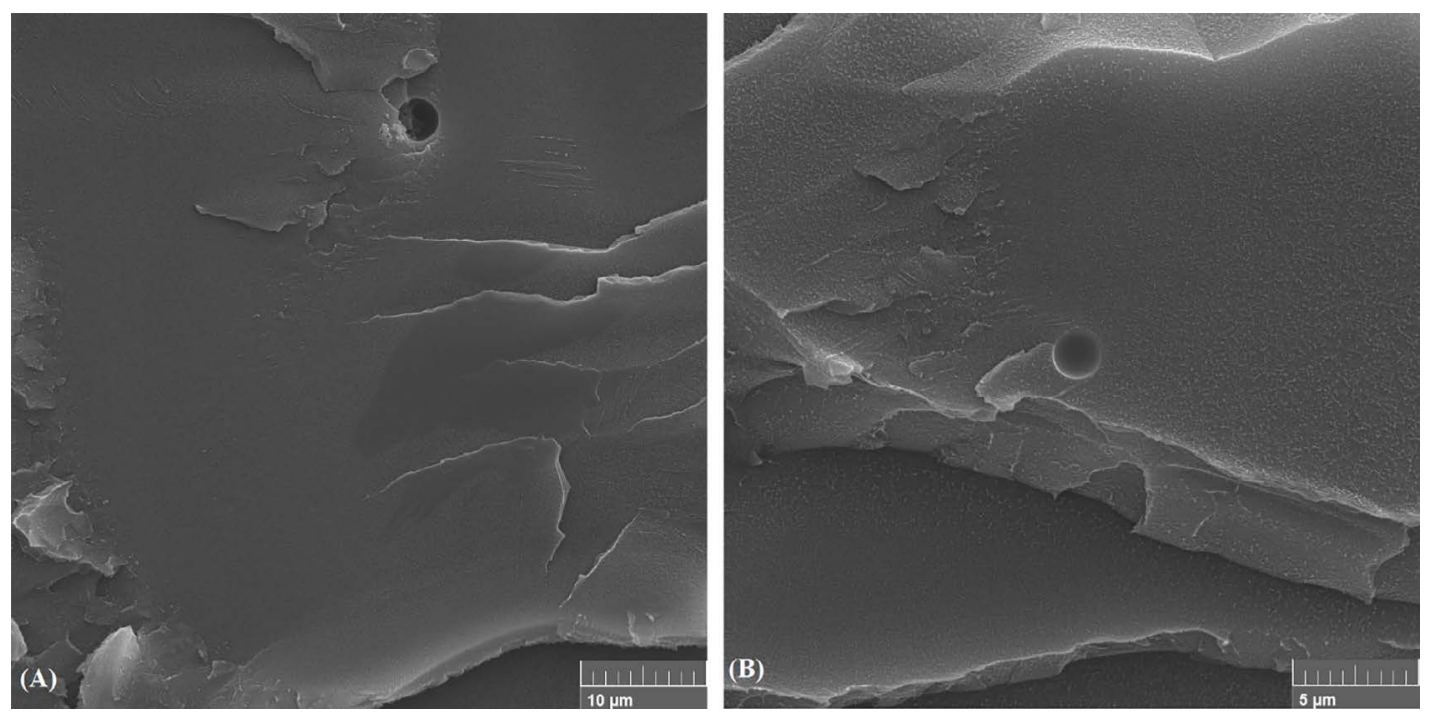

Figure 12. Micrographs of the copolymers PS-AOL $55 \mathrm{kX}(\mathrm{A})$ and $10 \mathrm{kX}(\mathrm{B})$.
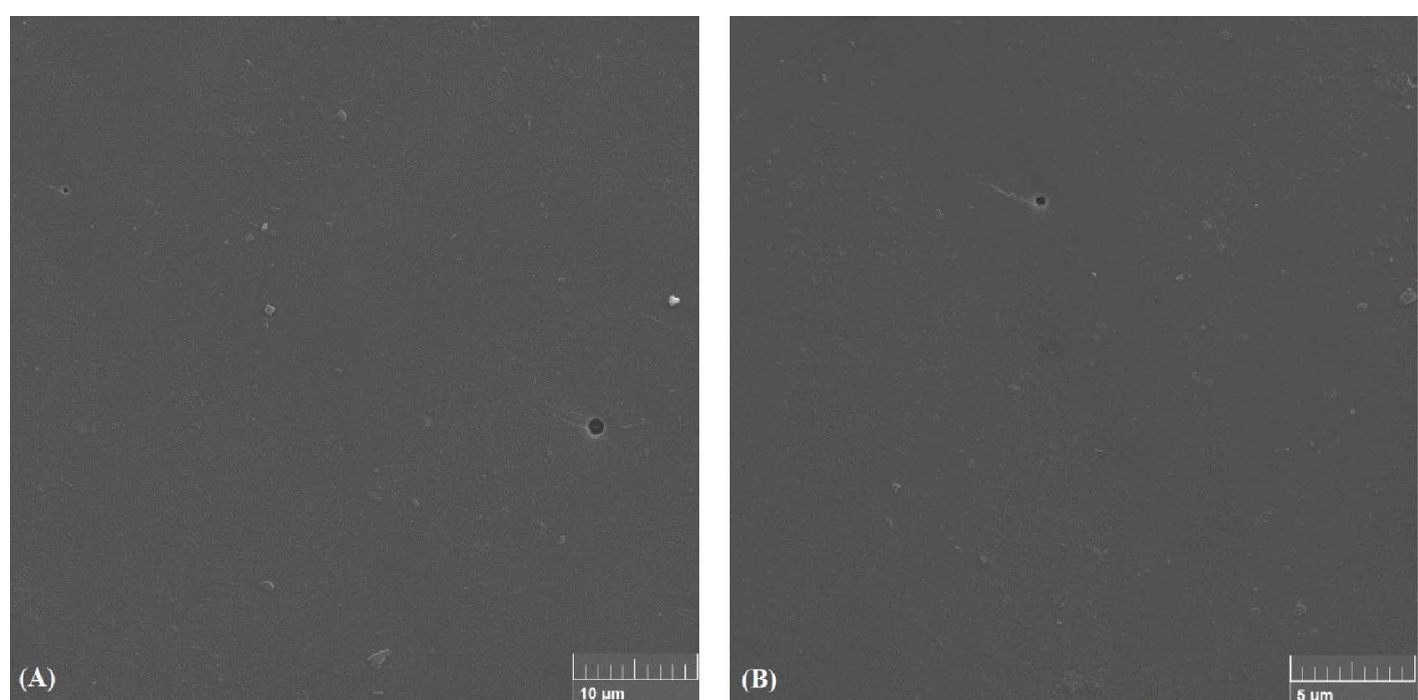

Figure 13. Micrographs of the copolymers PS-AOL $105 \mathrm{kX}$ (A) and $10 \mathrm{kX}$ (B).
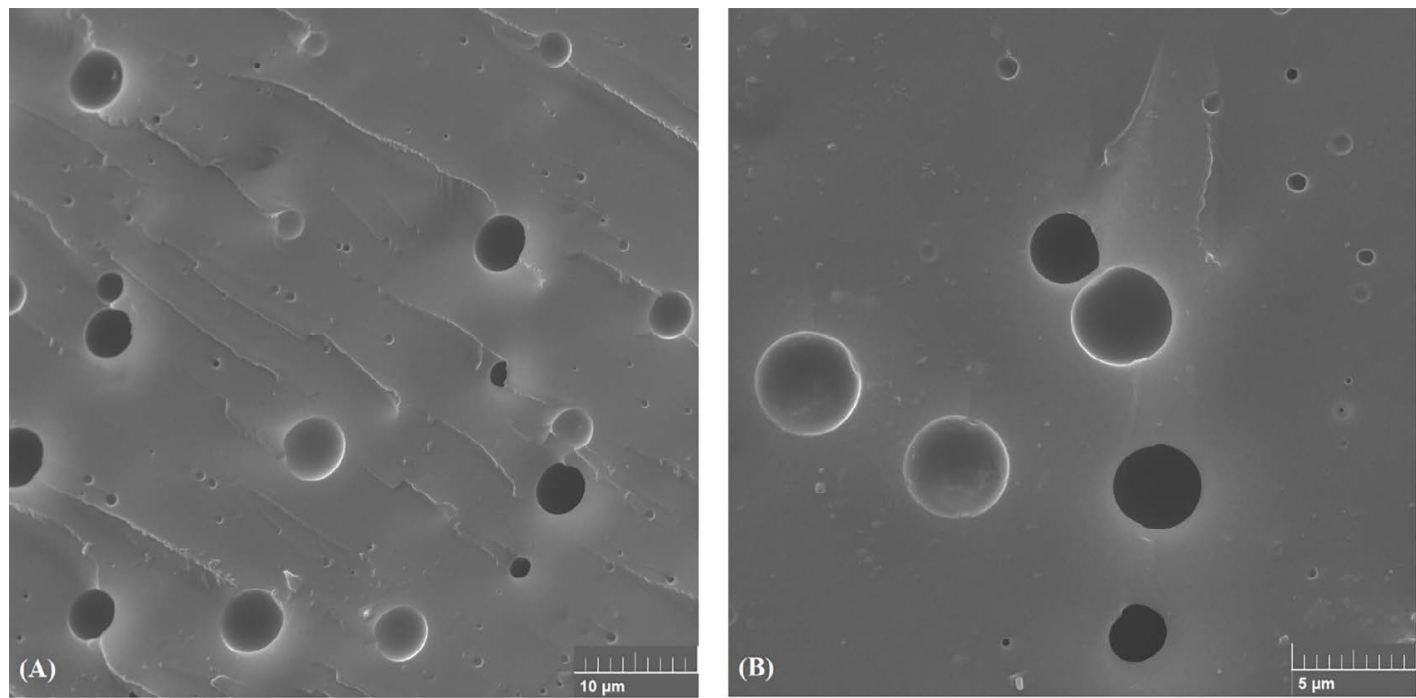

Figure 14. Micrographs of the copolymers PS-AOL $155 \mathrm{kX}(\mathrm{A})$ and $10 \mathrm{kX}(\mathrm{B})$. 

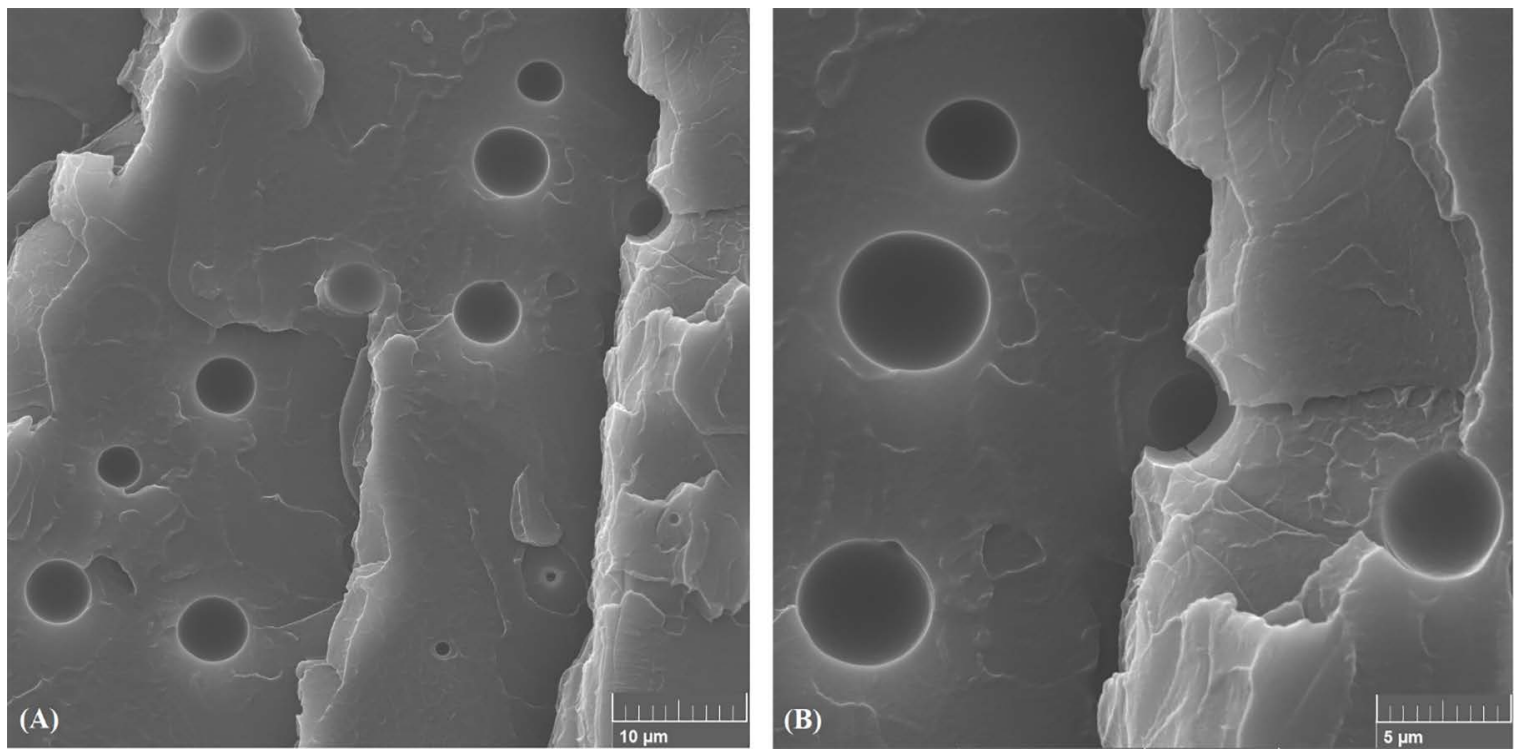

Figure 15. Micrographs of the copolymers PS-OAC $55 \mathrm{kX}(\mathrm{A})$ and $10 \mathrm{kX}(\mathrm{B})$.
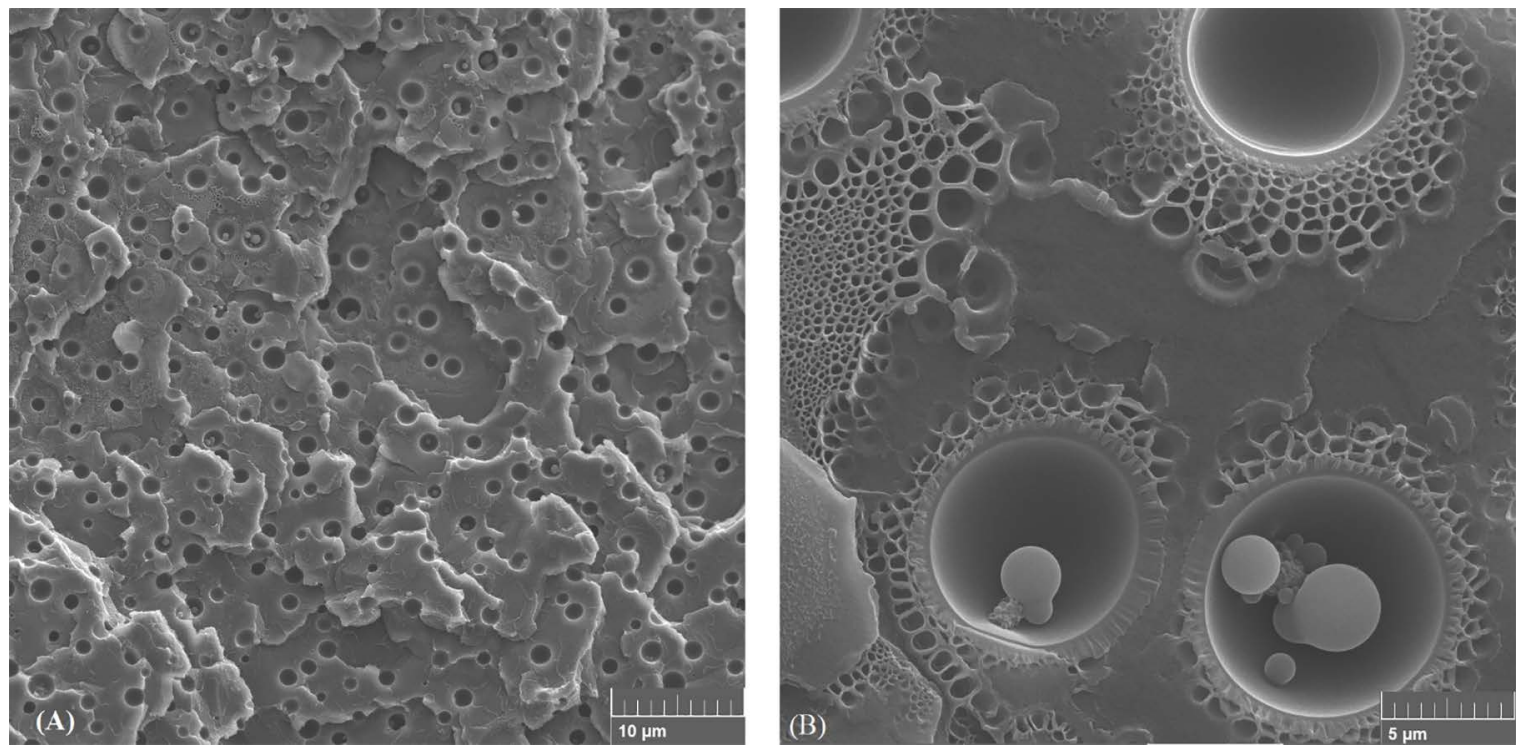

Figure 16. Micrographs of the copolymers PS-OAC $105 \mathrm{kX}(\mathrm{A})$ and $10 \mathrm{kX}(\mathrm{B})$.

The micrographies revealed single-phase surfaces for the compositions containing 2 or $5 \%$ oleate, indicating the homogeneity of the samples. For that ones with 10 and $15 \%$ of ester content, it is possible to observe small hollows, which were filled by the excess of allyl oleate. This fact suggests that these compositions are heterogeneous. SEM evaluation of oleic acid compositions revealed biphasic materials, even at lowest concentrations.

The SEM data corroborate with the ${ }^{1} \mathrm{H}-\mathrm{NMR}$ and DSC results, whereby, at the concentrations of 2 and $5 \%$, the oleate reacted and the higher concentration ( $5 \%$ ) can be considered as the saturation limit of the composition. Above this value, part of the oleate reacts and part remains embedded as a physical mixture. The compositions with oleic acid are all as just physical mixture, at the two concentrations employed, 5 and $10 \%$.

\section{Conclusions}

The allyl oleate ester was satisfactorily obtained under acid catalysis and it was used in compositions with styrene. The methodology used was able to show that the internal unsaturation of fatty materials, oleic acid or allyl oleate, does not react under any of the conditions employed. The copolymerization reaction occured by the terminal unsaturation of the allyl oleate with styrene until oleate reach the saturation limit. It is possible, therefore, to compatibilize the styrene with a renewable matrix, easy to be synthesized and accessible as allyl ester, for the formation of new materials based on polystyrene. 


\section{Acknowledgements}

The authors thank to CNPq - Brazil and CAPES - Brazil finance code 001) for the financial support and to Federal University of Paraná (UFPR) for the laboratory infrastructure.

\section{References}

1. Canevarolo Junior SV. Ciência dos Polimeros. São Paulo: Artliber; 2002.

2. Lokensgard E. Plásticos Industriais: Teoria e Aplicações. São Paulo: Cengage Learning; 2014.

3. Espino-Pérez E, Gilbert RG, Domenek S, Brochier-Salon MC, Belgacem MN, Bras J. Nanocomposites with functionalized polysaccharide nanocrystals through aqueous free radical polymerization promoted by ozonolysis. Carbohydrate Polymers. 2016;135:256-266.

4. Pereira GB, Pereira GC, Lima M, Jesus B, Silva EA, Benini KCC, et al. Featuring High Impact Polystyrene Composites Strengthened with Green Coconut Fiber Developed for Automotive Industry Application. Journal of Research Updates in Polymer Science. 2017;6(1):17-20.

5. Hillburg LS, Elder AN, Chung H, Ferebee RL, Bockstaller MR, Washburn NR. A universal route towards thermoplastic lignin composites with improved mechanical properties. Polymer. 2014;55(4):995-1003.

6. Kekez B, Gojgić-Cvijović G, Jakovljević D, Pavlović V, Beškoski V, Popović A, et al. Synthesis and characterization of a new type of levan-graft-polystyrene copolymer. Carbohydrate Polymers. 2016;154:20-29.

7. Men Y, Du X, Shen J, Wang L, Lui Z. Preparation of corn starch-g-polystyrene copolymer in ionic liquid:1-Ethyl-3-methylimidazolium acetate. Carbohydrate Polymers. 2015;121:348-354.

8. Sharma V, Kundu PP. Addition polymer from natural oils-A review. Progress in Polymer Science. 2006;31(11):983-1008.
9. Lee SY, Song JM, Sohn JY, Shul YG, Shin JW. Radiation-induced crosslinking of poly (styrene-butadiene-styrene) block copolymers and their sulfonation. Nuclear Instruments and Methods in Physics Research Section B: Beam Interactions with Materials and Atoms. 2013;316:71-75.

10. Coutinho FMB, Oliveira CMF. Reações de Polimerização em Cadeia: Mecanismo e Cinética. Rio de Janeiro: Interciência; 2006.

11. Lu Y, Larock RC. Novel polymeric materials from vegetable oils and vinyl monomers: preparation, properties, and applications. ChemSusChem. 2009;2(2):136-147.

12. Rosset IG, Cavalheiro MCHT, Assaf EM, Porto ALM. Enzymatic Esterification of Oleic Acid with Aliphatic Alcohols for the Biodiesel Production by Candida antarctica Lipase. Catalysis Letters. 2013;143(9):863-872.

13. Froehner S, Leithold J, Lima Júnior LF. Transesterification of vegetable oils: characterization by thin-layer cromatography and density. Quimica Nova. 2007;30(8):2016-2019.

14. Pavia DL, Lampman GM, Kriz GS, Vyvyan JR. Introdução à Espectroscopia. São Paulo: Cengage Learning; 2010.

15. Wang C, Jiao GS, Zhu BL, Peng L, He WM, Zhao LP. Modification of cyanate resin by conjugated tri-component interpenetrating polymer networks. Journal of Materials Research and Technology. 2017;6(3):226-231.

16. Canevarolo Junior SV, coord. Técnicas de Caracterização de Polímeros. São Paulo: Artliber; 2004.

17. Rampazzo V. Avaliação da degradação térmica de óleos vegetais por termogravimetria, cromatografia gasosa e espectroscopia de infravermelho médio. [Dissertation]. Curitiba: Federal University of Paraná; 2015. 